\title{
Relendo a perspectividade. Algumas notas sobre "o perspectivismo de Nietzsche"
}

\author{
Jakob Dellinger**
}

\begin{abstract}
Resumo: Este texto contrasta o entendimento comum do "perspectivismo de Nietzsche" com o seu uso da palavra "Perspektive" e termos semelhantes. As primeiras seções proporcionam uma breve pesquisa do desenvolvimento dos diversos significados através da carreira de Nietzsche e a influência de Gustav Teichmüller. As seções subsequentes revelam alguns problemas de leituras comuns do perspectivismo, como a teoria do conhecimento de Nietzsche. Discutindo os assuntos de falsificação, objetividade e autorreferência, as seções remanescentes levam à conclusão que o perspectivismo não deve ser entendido como a doutrina epistemológica de Nietzsche, mas como algo que não o deixa criar tal doutrina.
\end{abstract}

Palavras-Chave: perspectivismo - falsificação - objetividade autorreferência -Teichmüller

A bibliografia sobre Nietzsche em Weimar lista 164 publicações sobre "Perspektivismus" até 20071. Acrescentando publicações mais recentes, aquelas não documentadas, bem como textos com um escopo mais geral, o número de discussões relevantes sobre o "perspectivismo de Nietzsche" pode, no mínimo, dobrar. Falar do "perspectivismo de Nietzsche" é comum, e vai muito além do

\footnotetext{
* Tradução de Eduardo Nasser.

** Doutorando na Universidade de Vienna, colaborador do Nietzsche-Lexikon e membro do Nietzsche Research Group. Email: j.dellinger@overclockers.at

1 http://ora-web.swkk.de/swk-db/niebiblio/index.html (10 de abril de 2011).
} 
campo dos estudos especializados de Nietzsche, muito como falar do "empirismo de Hume" ou o "idealismo de Fichte". Pode, portanto, parecer uma surpresa para alguns que, através do texto da KSA, o termo "Perspektivismus" é usado somente algumas vezes e que, como veremos, se mantêm de certa forma incerto se Nietzsche inclusive o entende como um rótulo para a sua posição filosófica. Desnecessário dizer que isto não sentencia de antemão se faz ou não sentido falar do "perspectivismo de Nietzsche" per se. Deve haver boas razões para fazê-lo, mesmo que ele não tenha declarado explicitamente sua filosofia como uma forma de perspectivismo. Afinal, nós não poderíamos nos abster de chamar Hume um empirista somente porque ele mesmo parece nunca ter usado a palavra "empirismo". Porém, esta é uma situação diferente na medida em que Nietzsche usa, frequentemente, palavras como "Perpspektive", "perspektivisch" e, embora algumas vezes somente, "Perspektivismus". Apesar da enorme quantidade de literatura sobre o "perspectivismo de Nietzsche", surpreendentemente, porém, pouca atenção acadêmica foi dada à análise de como ele usa estas palavras. Baseado em pesquisas feitas para o Nietzsche-Wörterbuch, o presente artigo tenta dar algumas pistas sobre como o seu vocabulário do perspectivístico se relaciona a imagens comuns do "perspectivismo de Nietzsche"2.

\section{Desenvolvimentos e significados}

A palavra "Perspektive", e termos relacionados como "perspektivisch", podem ser encontrados nos escritos de Nietzsche desde cedo, mas o seu uso permanece esporádico até o início dos anos 1880. Das quase duzentas ocorrências no corpus da KSA, somente

2 Como meu foco é demonstrar o que podemos ganhar analisando de perto a linguagem de Nietzsche, estarei me restringindo a um mínimo no que diz respeito a discussão de literaturas secundárias. Para um breve panorama, ver Dellinger (2009). 
Relendo a perspectividade. Algumas notas sobre "o perspectivismo de Nietzsche".

algumas podem ser encontradas em cadernos dos anos 1870. Em contraste, o termo "Perspektive" ocorre o dobro de vezes durante um primeiro aumento entre 1881-1882, e depois de uma queda em 1883, anotações de 1884, por si só, contêm mais de vinte exemplos. Nos anos subsequentes, Nietzche continua usando este vocabulário extensivamente, tanto em suas anotações quanto em suas obras publicadas.

Esta clara prevalência quantitativa entre os anos 1884-1888 está ligada intimamente a uma mudança qualitativa distinta: como veremos, uma variedade de diferentes significados podem ser distinguidos quando vemos em que contextos Nietzsche usa as várias formas da palavra "Perspektive", mas o significado que é comumente associado com o tema do perspectivismo, bem como com a fala característica do "perspectivístico" em sua forma nominal, começa a se desenvolver paralelamente ao forte aumento de ocorrências em 1884.

Antes deste período, o uso de Nietzsche está voltado predominantemente para os significados que eram comuns em sua época. O exemplo mais óbvio é o que seria considerado provavelmente o significado mais "literal" da palavra hoje, a saber, aquele relacionado à percepção visual dos objetos espaciais e sua diminuição relativa a um ponto de vista particular. Por exemplo, em uma anotação de 1871, Nietzsche explica que no teatro grego, atores tinham que ser colocados num lugar mais alto para serem vistos pela platéia, apesar das "circunstâncias perspectivísticas", ou maiores distâncias (cf. Nachlass/PF 1871, 25[1], KSA 7.568). Outro domínio de significado que era muito comum no século XIX, e que teve um papel importante, tanto para cunhar o termo na renascença, bem como em suas primeiras ressonâncias filosóficas, é o da pintura. Neste sentido, Nietzsche, por exemplo, afirma que algumas paisagens só podem ser pintadas de forma adequada a partir da perspectiva do olho do pássaro (cf. WS/AS 138, KSA 2.612). Nietzsche também emprega a palavra "Perspektive" em um sentido temporal, comum em sua época, e que ainda hoje o é na Alemanha. O termo aproxima-se da 
"Aussicht" alemã quando Nietzsche se refere à "perspectiva de uma nova era" (Nachlass/PF 1870, NL 5[88], KSA 7.116) ${ }^{3}$ ou fala a seu amigo Rohde que ele encontrou um velho conhecido o qual ele descreve como uma figura desesperada, "sem perspectivas" (a E. Rohde 7.6.1871, KSB 3.197). Todos esses significados podem ser encontrados similarmente entre os contemporâneos de Nietzsche e, com algumas exceções discutíveis de 1881 e 1882, que poderiam ser vistas como os primeiros indícios da mudança que ocorre em 1884 (cf. por exemplo Nachlass/PF 1881, 15[9], KSA 9.636f), geralmente não tem um papel importante na estrutura conceitual que ele usa para discutir as suas ideias filosóficas. Eles poderiam, portanto, ser qualificados como "convencionais" $\mathrm{em}$ contraste com o significado que é comumente associado ao "perspectivismo", que comporta uma característica e pretensão filosófica complexa e que poderia, portanto, ser descrito como uma "expressão técnica" 5 ou "terminológica". O contraste com os exemplos discutidos acima tornam-se evidentes quando olhamos para como este significado "terminológico" é usado na seguinte passagem de 1886:

Devias aprender a conceber o perspectivístico de toda estima de valor - o deslocamento, a distorção teleologia aparente dos horizontes e de tudo aquilo que pertence ao perspectivístico; e também a parte da estupidez referente a valores opostos e a toda penitência intelectual com que se faz pagar todo pró, todo contra. Devias aprender a conceber a injustiça necessária de todo pró e contra, a injustiça como indissociável

3 As traduções dos fragmentos póstumos cuja indicação do tradutor estão ausentes foram feitas por André Mota Itaparica (NE).

$4 \mathrm{Um}$ primeiro significado não convencional que atecipa, de alguma forma, aquele que se desenvolve após 1884 aparece em HL/CO Ext. II quando Nietzsche associa intimamente "Perspektive" com "Horizont". Ambos os termos aqui evocam a imagem de um horizonte de sentido calmo, fechado, que tem a função de possibilitar a vida e é destroçada pelo que ele chama de "Historie" ou "historischer Sinn" (c.f. HL/CO Ext. II, 4, KSA 1.272 and 319-323).

5 Small $(2001,47)$. 
Relendo a perspectividade. Algumas notas sobre "o perspectivismo de Nietzsche".

da vida, a vida como condicionada pelo perspectivístico e sua injustiça. (MA I/HH I, Prefácio 6, KSA 2.220)

Este trecho demonstra diversos atributos típicos do significado terminológico como avaliação, simplificação, injustiça necessária e, por último, que a perspectiva é, como Nietzsche não cessa de repetir, uma condição necessária da vida. Enquanto os aspectos de distorção e aparência ainda evocam analogias com o significado visual, é enfatizando as características previamente mencionadas que o significado vai além do convencional ou suas extensões metafóricas diretas.

Isto pode ser visto comparando um aforismo curto de $\mathrm{FW} / \mathrm{GC}$ com uma anotação de 1884. O primeiro depende de uma extensão metafórica do significado visual para caracterizar "egoísmo" enquanto o último recupera este tema adicionando aspectos do significado terminológico, lhe oferecendo uma guinada mais radical:

Egoísmo é a lei da perspectiva no âmbito do sentimento, segundo a qual está próximo parece grande e pesado; e, à medida que se afastam, todas as coisas decrescem no tamanho e peso (FW/GC 162, KSA 3.498. Trad. Paulo César de Souza, p. 164).

Egoísmo como o ver e julgar perspectivos de todas as coisas com fins de conservação: todo ver (o fato de que em geral algo é percebido, esse selecionar) já é uma valoração, uma aceitação, em oposição a um rejeitar e não-querer-ver) (Nachlass/PF 1884, 26[71], KSA 11.167).

Enquanto FW/GC 162 alude ao domínio do prático através de seu título e da palavra "Empfindung", a orientação para necessidades práticas é feita de forma explícita na anotação tardia: o ver perspectivo serve o propósito da preservação e é descrito como uma forma de avaliação. Combinado com o tema do juízo, isto também sugere um sentido mais forte de atividade do que $\mathrm{FW} /$ GC 162. A principal diferença, porém, está no aspecto da seleção. 
Não é mais sobre ver diferenças de tamanho, grande ou pequeno, mas antes de ver ou não ver, aceitar ou rejeitar, o que traz à mente os temas de interpretação e simplificação, fatores chave do significado terminológico. Este exemplo deve mostrar como o significado terminológico é, por um lado, baseado em significados mais convencionais, mas, por outro, vai além deles por introduzir aspectos que não podem (ou, pelo menos, não facilmente) ser derivados da noção visual de perspectividade.

Ao mesmo tempo em que o significado terminológico tornase parte característica do vocabulário filosófico de Nietzsche, ele também começa a usar os significados mais convencionais de forma regular e com novas variações. Um destes significados que ele emprega frequentemente na segunda metade dos anos 1880 compreende maneiras específicas de pensar, ou visões em geral, como "perspectivísticas". Neste sentido, por exemplo, Nietzsche antecipa que ZA somente começará a vender e ter efeito depois que o público se tornar mais familiarizado com seus "pensamentos e perspectivas" (para E.W. Fritzsch 16.8.1886, KSB 7.228).

Aspectos como "Schein", simplificação, avaliação ou necessidade para a vida são geralmente implicados de forma velada em passagens nas quais Nietzsche fala de visões como "perspectivas", podendo ainda ser, portanto, diferenciados do significado terminológico em um nível semântico. O mesmo vale para a frase "sob a perspectiva de", que é usada frequentemente depois de 1884. Nietzsche também mistura, porém, significados terminológicos com os mais convencionais, então pode ser eventualmente difícil dizer se há ressonância do significado terminológico ou não.

De qualquer forma, discernir os diferentes significados e períodos em que Nietzsche os usa tem muitas consequências importantes. Por exemplo, isto significa que nem todos os trechos em que Nietzsche usa estes termos podem estar diretamente relacionados ao que ele chama de "perspectivismo". Também significa que devemos ter especial cuidado ao falarmos sobre "perspectivismo" quando discutindo textos anteriores a 1884. Porém, talvez o mais importante 
seja que isso significa que enquanto tentamos interpretar o que Nietzsche diz sobre a perspectiva e o perspectivismo (ao invés de usar "perspectivismo" simplesmente como um rótulo interpretativo), não devemos nos deixar ser guiados por argumentos que dependem fortemente de significados mais convencionais. Voltarei a isto mais tarde, mas primeiro tocarei num antecedente importante para o desenvolvimento do significado terminológico.

\section{A influência de Gustav Teichmüller}

Foi descoberto há muito tempo que o discurso característico de Nietzsche sobre o perspectivístico foi inspirado pelas suas leituras da obra Die wirkliche und die scheinbare Welt (1882), de Gustav Teichmüller. ${ }^{6}$ Teichmüller foi um colega de Nietzsche em Basel, mas se mudou para Dorpat (Estônia, então parte da Rússia) em 1871. Os dois não parecem ter tido uma relação muito próxima, e nem mantiveram correspondências, mas Teichmüller enviava seu trabalho regularmente para Franz Overbeck, que repassou Über die Reihenfolge der platonischen Dialoge para Nietzsche em 1879, e também emprestou outros dois trabalhos em 1883, um dos quais provavelmente foi Die wirkliche und die scheinbare Welt.

Teichmüller desenvolveu seu conceito do perspectivístico em Darwinismus und Philosophie (1877) e Über das Wesen der Liebe (1879), mas não fez uso dele em seu pequeno estudo da cronologia dos diálogos de Platão que Nietzsche leu. Apesar de não termos evidências de que Nietzsche leu os primeiros dois trabalhos, ele leu a longa crítica de Otto Caspari ao livro de Teichmüller sobre

6 Cf. NOHL (1913). Para comentários mais recentes sobre Nietzsche e Teichmüller, ver SMALL , 2001, p.41-58 e

BROBJER, 2008, p.52 e p. 96 e segs. SCHWENKE, 2006, oferece uma visão eficaz do desenvolvimento de Teichmüller. 
o darwinismo ${ }^{7}$. Caspari discute o entendimento de Teichmüller sobre o tempo e cita sua tese de que o tempo não é nada além de uma "aparência perspectiva da ordem sem tempo do mundo"8 ou, como ele mesmo coloca, "mera aparência, induzida através da perspectiva de nosso ponto de vista particular, restrito" ". Enquanto permanece incerto se este pequeno trecho, e as duas paráfrases que captam a terminologia característica de Teichmüller, influenciaram realmente a linguagem de Nietzsche, é mais ou menos nesta época que ele começa a usar o termo mais frequentemente, e, em alguns pontos, parece antecipar a mudança para o significado terminológico. Ainda que antes de 1884 não possamos ver o significado terminológico desvendar-se claramente, é uma suposição segura de que a maior influência veio de Die wirkliche und die scheinbare Welt, o qual Nietzsche parece ter lido pela primeira vez em $1883^{10}$. Teichmüller, ele mesmo, usa a palavra com significados variados, criando tensões interessantes em seu sistema metafísico, mas terei que me restringir a somente alguns comentários aqui.

Em seu prefácio, Teichmüller descreve todos os sistemas filosóficos anteriores como "meras imagens perspectivísticas" ${ }^{\text {"11 }}$ na medida em que eles projetam determinados conteúdos ou conceitos metafísicos dentro da realidade. Estes são, de acordo com Teichmüller, de natureza meramente ideal em oposição ao sujeito que projeta, que é, para ele, o ser verdadeiramente substancial. Como deixa claro o subtítulo("Neue Grundlegung der Metaphysik"), o objetivo de Teichmüller em desbancar essas projeções de perspectivas é o de proporcionar um novo fundamento para a metafísica girando em torno de uma nova concepção de sujeito, concepção

7 CASPARI, 1881, p.141-184.

8 Ibid., p.169.

9 Ibid., p.167.

10 Cf. BROBJER, 2008, p.52.

11 TEICHMÜLLER, 1882, p.XVI.

134 | cadernos Nietzsche 31, 2012 
que ele acha que foi até agora subestimada na filosofia e só verdadeiramente apreciada na idéia cristã de um Deus pessoal ${ }^{12}$.

Constantemente contrastando o mundo aparente, perspectivístico com o mundo real, Teichmüller conecta o seu conceito de perspectivístico com diferentes formas de distinção aparência/realidade. Por exemplo, ele descreve o movimento das estrelas, como observado da terra, meramente como aparência perspectivística, em oposição ao verdadeiro conhecimento da sua natureza, proporcionado pela astronomia ${ }^{13}$. Considerando que Nietzsche assimilou a forte associação do "perspektivisch" e "scheinbar", ele abandonou a oposição a uma realidade não-perspectivística que pode ser revelada através da razão.

Alguns dos significados encontrados em Teichmüller não dependem de uma dicotomia aparência/realidade e, inclusive, tendem a solapá-la. Tomemos os exemplos dos partidos políticos que têm diferentes idéias sobre uma nova lei e de um gato pegando um rato. Seu "entendimento das coisas", como ele explica, está perspectivamente relacionado a seu ponto de vista, então enquanto o partido liberal promove uma nova lei, o conservador rejeita; enquanto o rato irá lamentar, o gato está satisfeito ${ }^{14}$. Este contexto "prático" não só forma um pano de fundo importante para o uso terminológico de Nietzsche, bem como para a sua classificação de certas visões ou formas de pensar como "perspectivas", mas também sugere que diferentes perspectivas não podem ser facilmente transcendidas em direção a uma ordem objetiva.

Mais interessante ainda, talvez, são aquelas tendências no vocabulário de Teichmüller que parecem reduzir as distinções aparência/realidade, tal como invocado pelo entendimento visual da perspectividade. Teichmüller segue, de maneira vaga, as concepções de tempo e espaço de Kant como formas de intuição, quando

12 Cf. ibid., 348 e segs.

13 Ibid., p.XX.

14 Ibid., p.185. 
ele descreve espaço, tempo, coisidade ("Ding") e movimento como "formas de intuição perspectivísticas" que são estritamente subjetivas e que "não tem nada a ver com a realidade"15. Porém, ao comparar diversas perspectivas, nós podemos, de acordo com Teichmüller, transcender suas origens subjetivas e alcançar o que ele chama de espaço "geométrico" ou tempo "objetivo"16. Nesse ponto, porém, ele nega explicitamente a óbvia analogia com o significado visual: enquanto nossa "teoria comum de perspectiva" supõe que a ordem objetiva, geométrica é anterior à imagem perspectivística, ele argumenta que é, na verdade, o contrário, e a ordem objetiva deve ser considerada um "produto tardio do intelecto"17. Teichmüller entende, por vezes, certas operações do intelecto (como sintetizar a multiplicidade dada pelos sentidos) como "perspectivística" também ${ }^{18}$ e a sua admissão que a ordem geométrica objetiva é um produto de nosso intelecto literalmente parece levar alguém como Nietzsche a se perguntar se esta ordem não é ela mesma perspectivística.

Embora não devesse ser necessário discutir que Nietzsche se opôs ao conceito de sujeito como substância verdadeira de Teichmüller, bem como seu entendimento da razão como meio de transcender o mundo aparente, perspectivístico para uma realidade objetiva, deve ser notado também que diversos atributos cruciais para o significado terminológico de Nietzsche, como sua noção de interpretação, não estão, ou não aparecem estar, no vocabulário de Teichmüller. Outros temas como ilusão, erro e decepção, aparecem ocasionalmente, mas foram claramente radicalizados e expandidos

15 Ibid., p.186. A noção de "formas perspectivísticas" sobreviveu na linguagem de Nietzsche, mas perdeu o sentido sistemático unificado que Teichmüller atribuía. Enquanto suas discussões de formas perspectivísticas de tempo e espaço tomam quase cem páginas, Nietzsche só fala de diferentes "perspektivische Formen" em FW/GC 374 e

Nachlass/PF 1885, NL 40[39], KSA 11.648 e seg.

16 TEICHMÜLLER, 1882, p.271.

17 Ibid., p.216.

18 Cf. ibid., p.19 e seg. e p.37. 
por Nietzsche. Na medida em que se pode ver similitudes entre a fala de Nietzsche sobre a simplificação e a generalização e o entendimento de Teichmüller da "imagem perspectivística" como síntese do múltiplo, ele parece restringir este aspecto ao domínio da percepção sensorial, enquanto Nietzsche usa-o num sentido mais amplo. Além disso, como vimos, Teichmüller emprega o conceito em domínios que podem ser qualificados como "práticos", mas ele não vai tão longe quanto Nietzsche, que enfatiza repetidamente que perspectivas estão sempre relacionadas às necessidades e interesses de formas específicas de vida. Comparado à insistência de Nietzsche de que o perspectivístico é uma condição necessária para a vida, Teichmüller está numa via completamente diferente quando ele acentua o quão crucial é para a nossa comunicação transcender a aparência perspectivística para uma ordem objetiva ${ }^{19}$.

Não deve ser ignorado que muitos dos temas que tomam forma no vocabulário de Nietzsche sobre o perspectivístico a partir 1884 em diante já estão presentes em seu pensamento antes disso. Por exemplo, o aspecto simplificador pode ser detectado em suas primeiras críticas da linguagem. Apontamentos similares podem ser feitos sobre "Schein", ilusão ou sua necessidade para a vida. Desse modo, enquanto é inegável que a noção de Teichmüller do perspectivístico teve um impacto significativo em Nietzsche, ele também foi inteiramente transformado e integrado à sua estrutura filosófica.

\section{"Perspektivismus"}

Trataremos agora do termo "Perspektivismus" enquanto tal. Teichmüller parece não ter usado a expressão, e nenhuma outra fonte foi identificada até então, portanto, as chances são grandes de

19 Ibid., 27lf. 
que o termo foi cunhado pelo próprio Nietzsche. No geral, existem cinco ocorrências do termo, além de uma outra - "BewußtseinsPerspektivism" - encontradas na KSA. A primeira data de 1886, está localizada em FW/GC 354, bem como em duas notas não publicadas (Nachlass/PF 1886, 7[21], KSA 12.303 and 7[60], KSA 12.315). As outras estão em uma anotação tardia (Nachlass/PF 1888, 14[186], KSA 13.373). Consequentemente, pode ser notado sem ser preciso discutir com profundidade estes textos, algo que vai muito além do escopo deste artigo, que Nietzsche não usou o termo "Perspektivismus" de forma regular a fim de oferecer um rótulo unificado, ou uma identificação, de uma determinada "teoria", "doutrina" ou mesmo de sua abordagem filosófica num sentido mais geral. Corremos o risco, ao destacarmos este ponto, de falar o óbvio, mas ainda assim parece justificável, pois é precisamente a imagem que muitas discussões ou referências sobre o "perspectivismo de Nietzsche" provocam.

Poderíamos nos perguntar se Nietzsche, nestes poucos textos, usa "Perspektivismus" para rotular uma teoria filosófica ou doutrina ou, como discutiu Robin Small ${ }^{20}$, somente para descrever um certo fenômeno $^{21}$. As referências de Nietzsche ao perspectivismo em FW/GC ("Isto é propriamente o fenomenalismo e perspectivismo, assim como eu o entendo“, FW/GC 354, KSA 3.593. trad. Rubens Rodrigues Torres Filho, Os pensadores, 1974, p. 225) e Nachlass/ PF 1886, 7[60], KSA 12.315 podem discutivelmente ser lidas nas duas formas ${ }^{22} \mathrm{e}$, portanto, pode não haver uma resposta definitiva a esta pergunta. A curta nota "perspectivismo da desejabilidade

20 Cf. SMALL, 2001, p.48.

21 Uma diferença semelhante no uso dos dois "isms" alemães pode ser observada em Kant, que fala do "esquematismo transcendental" para denotar um fenômeno que ele discute e do "idealismo transcendental" para caracterizar a sua própria abordagem.

22 Uma observação similar poderia ser feita, marca Small, com respeito ao uso de Nietzsche de "Phänomenalismus". Enquanto claramente denota uma posição na epistemologia em AC 20, dificilmente pode ser lida da mesma forma quando ele fala de um "fenomenalismo do "mundo interior"' (Nachlass/PF 1888, 15[90], KSA 13.458). 
(do ideal)" (Nachlass/PF 1886, 7[21], KSA 12.303), bem como os exemplos na nota de 1888, não podem ser acolhidas, porém, como declarações de uma posição filosófica ou doutrina. Por exemplo, na frase "o átomo que eles postulam é inferido segundo a lógica daquele perspectivismo da consciência - assim, é, ele mesmo, também uma ficção subjetiva" (Nachlass/PF 1888, 14[186], KSA 13.373), o termo parece expressar a perspectividade antropomórfica da consciência como um fenômeno e não como uma posição filosófica. Small, assim, sugere a leitura do "Perspektivismus" como sendo um sinônimo de "Perspektivität" para os dois últimos exemplos. Como Nietzsche usa esta expressão somente uma vez, as outras mais utilizadas "perspektivisch" e "das Perspektivische" podem ser, porém, pontos de referência mais adequados para o seu uso da linguagem. Entendido desta forma, o "ism" no perspectivismo enfatiza ou a natureza perspectivística de um certo domínio (como a consciência ou o "Wiinschbarkeit" de ideais) ou o que Nietzsche nomeia de uma maneira mais geral como a "necessidade do perspectivístico" (GT/NT, Preface 5, KSA 1.18). $\mathrm{O}$ "perspectivismo" poderia, portanto, ser entendido em ambos os sentidos discutidos, seja como um problema filosófico, ou como uma "posição" que é caracterizada, por anunciar a necessidade do perspectivístico. Como pretendo mostrar, porém, a seguir, esta "posição" pode não mais tomar a forma de uma teoria filosófica ou doutrina no sentido mais tradicional.

"Teoria" do conhecimento ou infinidade de interpretações?

O "perspectivismo de Nietzsche" é frequentemente interpretado como uma teoria do conhecimento de origem Kantiana ou neokantiana, ou seja, uma doutrina que tenta descrever como

23 Cf. SMALL, 2002, p.48. 
chegamos a objetos empíricos impondo esquemas conceituais sobre os dados sensoriais. Não entrarei em detalhes sobre as diferentes variações desta imagem comum, pois minha preocupação aqui é mais geral, a saber, que Nietzsche faz uso do significado terminológico em numerosos contextos que não pode ser explicado se estiver restrito ao domínio da experiência num sentido kantiano. Tome por exemplo a famosa passagem GM/GM III, 12, tida por muitos intérpretes como a expressão chave do "perspectivismo de Nietzsche". A alegação de que há somente um ver e "saber" perspectivístico é precedida pela discussão do ideal ascético na filosofia Vedanta e Kant. Os conceitos de conhecimento e perspectiva são introduzidas com respeito a diferenças no pensamento e avaliação filosófica: “devemos afinal, como homens do conhecimento, ser gratos a tais resolutas inversões das perspectivas e valorações costumeiras" (GM/GM III, 12, KSA 5.364. Trad. Paulo César de Souza, p. 108). Como notou acertadamente Christopher Janaway, Nietzsche pouco faz para fazer com que esse texto seja uma tentativa de dar uma contribuição séria à epistemologia ${ }^{24}$, e parece, antes de tudo, simplesmente não se preocupar com a percepção dos objetos empíricos.

Um bom exemplo de como Nietzsche oscila entre os diferentes contextos é dado por uma nota que começa no contexto da percepção referindo-se a um "mundo perspectivo (...) para o olho, tato e ouvido" e rapidamente muda para o contexto completamente diferente do "pensamento de processos da história" (Nachlass/PF 1884, NL 25[505], KSA 11.146). Nietzsche não parece demarcar uma linha clara para discernir entre o perspectivístico, como um problema da epistemologia, de diversos outros domínios, de modo que o conceito restringido a este campo não se adapta a seu uso da linguagem. Não iria tão longe quanto Ken Gemes, porém, que demanda uma leitura "antiepistemológica" do perspectivismo, mantendo que este serve primeiramente como forma terapêutica

24 Cf. JANAWAY, 2007, p.211. 
para liberar nossos impulsos ao invés de estar vinculado a questões sobre a natureza da crença ou conhecimento ${ }^{25}$. Muitas das passagens nas quais Nietzsche usa seu vocabulário do perspectivístico lidam, na realidade, precisamente com estas questões.

Outro ponto que torna duvidosa a interpretação do perspectivismo como uma ampla teoria neokantiana da experiência é que Nietzsche atribui "perspectivas" não só ao intelecto humano, ou à percepção de sujeitos individuais, mas também a sociedades, raças, estados, igrejas, crenças, culturas, centros de força, emoções, impulsos ou vontades de potência. Atribuir percepção sensorial, e sua esquematização conceitual, a sociedades ou impulsos certamente pareceria estranho.

Outro ponto de partida comum para as interpretações do "perspectivismos de Nietzsche" é a frase de efeito "Fatos é o que não há, e sim apenas interpretações" (Nachlass/PF 1886, 7[60], KSA12.315. Trad. Flávio Kothe, Fragmentos Finais, 2002, p. 164), tirada de uma nota que contém uma das poucas referências ao perspectivismo (sob aspas). Nietzsche explica sua tese dizendo "nós não podemos constatar nenhum fato "em si" (ibid.) e parece usar o termo perspectivismo para descrever que, assim como ele mantêm em FW/GC 374, existem infinitas possibilidades para interpretar “o mundo" e que nossos impulsos que governam nossas interpretações lutam para impor forçosamente suas perspectivas como a norma. Não há espaço para uma leitura completa da passagem, ou uma discussão sobre as objeções que foram feitas contra uma leitura profundamente interpretacionista aqui, mas no vocabulário de Nietzsche, as noções de perspectiva e interpretação são, de fato, tão interligadas que é difícil mantê-las à parte. $\mathrm{O}$ que gostaria de enfatizar é que ao compreendermos perspectivas enquanto formas de interpretação, podemos compreender muito melhor, tanto os diferentes contextos nos quais Nietzsche fala de "perspectivas",

25 Cf. GEMES, 2009. 
quanto os diferentes "temas" atribuidos a elas. Julgamentos morais, pensamento abstrato e percepção de objetos cotidianos podem todos ser razoavelmente entendidos como interpretações. Interpretações podem também ser mais ou menos atribuídas a indivíduos, impulsos (que guiam nosso entendimento, julgamentos morais, etc.) e até instituições ou grupos (que tem uma visão comum de algo). De qualquer forma, Nietzsche parece pensar que assim o é.

Passarei agora para três das principais questões em discussões recentes sobre perspectivismo, a saber, os problemas da "falsificação", objetividade e autorreferência. No desenvolvimento, tentarei iluminar as conexões entre perspectivas como interpretações e a não disponibilidade de um "an sich" mencionado no trecho acima.

\section{O problema da "falsificação"}

Debates recentes sobre o "perspectivismo de Nietzsche" frequentemente giram em torno do que foi chamado de "tese da falsificação" ${ }^{26}$ ou "teoria do erro" ${ }^{27}$. Em poucas palavras, a questão é se a noção de Nietzsche do perspectivistico implica alguma distorção da realidade e, portanto, pressupõe um conceito de realidade que ele frequentemente rejeita.

De fato, Nietzshce não só associa perspectivas com termos como "Ilusão", "Irrthum", "Täuschung" ou "Fälschung" repetidamente, mas também acentua estes aspectos em algumas das mais importantes discussões do perspectivístico, como FW/GC 354 ou os prefácios a MA I/HH I e GT/NT. Somente alguns exemplos:

Toda a vida repousa sobre a aparência, a arte, a ilusão, a óptica, a necessidade do perspectivismo e do erro (GT/NT, Prefácio 5, KSA 1.18. Trad. Paulo César de Souza, p. 19).

26 Cf. CLARK, 1990, p.96-126.

27 Cf. GREEN, 2002, p.58-94. 
Relendo a perspectividade. Algumas notas sobre "o perspectivismo de Nietzsche".

Lá falta o erro, a restrição perspectiva (Nachlass/PF 1885, 1[105], KSA 12.36).

Como é possível o erro? Mais corretamente: leis de conservação para processos duradouros pressupõem a ilusão perspectiva (Nachlass/PF 1884, 26[38], KSA 11.158).

Mas ninguém compreendeu o oposto, a inadequação da verdade para a vida e o condicionamento da vida à ilusão perspectiva (Nachlass/PF 1884, 26[334], KSA 11.238).

Não há nenhuma coisa em si, também nenhum conhecimento absoluto, o caráter perspectivo, enganador, pertence à existência (Nachlass/PF 1885, 34[120], KSA 11.460).

Isto deixa, então, Nietzsche imerso numa óbvia inconsistência? Pelo menos temos evidências claras de que ele estava ciente do assunto o qual é frequentemente acusado. Em uma nota de 1886, Nietzsche nega que o intelecto poderia criticar a ele mesmo porque, entre outras razões, isto iria pressupor que há algo "em si mesmo" além das apropriações perspectivísticas: "Isso já pressupõe que, fora de toda espécie de consideração e apropriação sensívelespiritual, houvesse algo, um em-si" (Nachlass/PF 1886, NL 5[11], KSA 12.188). Em outra nota do mesmo ano, Nietzsche argumenta contra a possibilidade de distinguir a "natureza das coisas" do "mundo aparente" e explica:

Para poder fazer tal diferenciação seria preciso pensar o nosso intelecto como contendo um caráter bastante contraditório: uma vez, orientado por uma visão perspectivística, como seria necessário para que seres da nossa espécie pudessem continuar existindo; outra vez, tendo ao mesmo tempo ainda uma capacidade de entender uma visão perspectivista como perspectivista, o fenômeno como fenômeno. Isso quer dizer: contando com uma crença na "realidade", como se esta 
fosse única, e tendo por outro lado a compreensão relativa a essa crença de que ela seria, por sua vez, apenas uma limitação perspectivista em relação a uma verdadeira realidade (Nachlass/PF 1886, NL 6[23] 12.241. Trad. Flávio Kothe, Fragmentos finais, 2002, p. 66)

Como podemos ver nesses trechos, Nietzsche estava ciente das dificuldades comumente associadas ao problema da falsificação. Ele, porém, não abre mão nem da noção do perspectivístico, nem de sua associação com diferentes aspectos da distorção. Também devemos ter em mente que ele nega explicitamente que aquilo que ele fala sobre o perspectivismo e sua "grande e radical corrupção, falsificação, superficialização e generalização" (FW/GC 354, KSA 3.593. Trad. Rubens Rodrigues Filho, Os pensadores, 1974, p. 226) é somente uma reprodução do velho problema do sujeito e objeto, ou aparência e coisa-em-si, o que inevitavelmente seria se o perspectivístico fosse entendido como uma distorção de uma realidade subjacente. Dentro de um único e mesmo parágrafo, Nietzsche sustenta que o «Perspektivismus» implica uma falsificação profunda e rejeita a inteligibilidade da oposição entre uma «coisa-em-si» e aparência.

Uma nota de 1886 vai ainda mais longe. Ao invés de explicar a falsificação através da apropriação indevida de uma realidade subjacente, ela alega que a falsificação perspectivística é necessária porque não há tal realidade:

A mais extremada forma de niilismo seria: que toda crença, todo tomar-por-verdadeiro é necessariamente falso: porque um mundo verdadeiro nem sequer existe. Portanto: uma aparência perspectivista, cuja origem reside em nós mesmos (na medida em que temos constantemente necessidade de um mundo mais estreito, estrito, restrito, simplificado (Nachlass/PF 1886, NL 9[41], KSA 12.354. Trad. Flávio Kothe, Fragmentos finais, 2002, p. 165). 
De que modo, então, faria sentido falar de falsificação ou simplificação? Alguns comentadores sugeriram que o tema da distorção e simplificação não deve ser entendido com relação a uma realidade subjacente, mas antes em relação a outras interpretações ou perspectivas ${ }^{28}$. Esta leitura realmente evita as dificuldades comumente associadas com a "tese da falsificação" e dá sentido ao argumento citado em que cada crença é inerentemente falsa pois não há mundo verdadeiro. Se não há mundo verdadeiro e fatos, mas somente uma infinidade de interpretações possíveis, então assumir certa perspectiva, formando uma crença ou "Für-wahrhalten", necessariamente implica uma simplificação profunda, no sentido de ignorar outras possibilidades, contextos, fundações, pontos de vista conflitantes e assim por diante. Quando Nietzsche se refere à „parte de estupidez referente a valores opostos e a toda penitência intelectual com que se faz pagar todo pró, todo contra" (MA I/HH I, Prefácio 6, KSA 2.20. Trad. Rubens Rodrigues Filho, Os pensadores, 1974, p. 97) como características necessárias do perspectivístico, a ignorância e o enfraquecimento intelectual estão claramente relacionadas a outras perspectivas e seus valores, não a uma realidade subjacente.

Outra passagem que fornece apoio para esta leitura é uma nota de 1885, na qual Nietzsche estabelece uma analogia às estruturas sociais e entende "o não-saber, o ver no grande e no grosseiro, o simplificar e falsificar, o perspectivo" (Nachlass/PF 1885, 40[21], KSA 11.639) como virtudes indispensáveis do governante que tem de simplificar a luta de seus súditos. Governantes e súditos devem, como destaca Nietzsche, ser entendidos como sendo do mesmo tipo, por isso mais uma vez, a simplificação perspectivística está relacionada a outras simplificações perspectivística, que resulta

28 Cf. e.g. SIMON, 1986, p.70, ABEL, 1989, p. 345 e seg., COX, 1999, p.165-168, COKER, 2002 , p.19. 
numa hierarquia flutuante de perspectivas ao invés de um esquema fixo de sujeito e objeto ou realidade subjacente e falsificação perspectivística.

\section{A questão da objetividade}

A referência de Nietzsche à "objetividade" (entre aspas) em GM/GM III, 12 levou alguns comentadores inferirem que a sua concepção do perspectivístico deve deixar espaço para uma forma de "objetividade modesta"29. "Perspectivismo", portanto, significaria somente que nunca podemos ter uma "visão de lugar algum" e, como sugere a analogia visual, combinando múltiplas perspectivas, teríamos um melhor, mais apropriado, entendimento do objeto em questão. Este entendimento invocado pela analogia visual parece ainda, porém, se apegar à concepção tradicional de objetividade: "objetividade" ainda significaria ver o objeto "como ele é", mesmo que isso só seja possível por uma aproximação e pela combinação de perspectivas. Isto voltaria a cair nos esquemas clássicos sujeito/objeto e aparência/realidade que Nietzsche repetidamente interroga ${ }^{30}$.

Embora a noção nietzschiana terminológica do perspectivístico ir além do uso metafórico do entendimento visual, não devemos tomar como certo que a pura analogia visual é esclarecedora para o que Nietzsche diz ${ }^{31}$. Como vimos, Teichmüller já negou ligações muito próximas ao significado visual, e na medida em que Nietzsche radicaliza geralmente sua concepção, seria surpreendente vê-lo reintroduzir a idéia de um objeto subjacente. Realmente, a descrição de Nietzsche da „objetividade“ como "a faculdade de ter seu pró e

29 LEITER, 1994, p.349.

30 Cf. ZITTEL, 2000, p.102, COX, 1999, p.164.

31 Cf. ibid., p.117. 
Relendo a perspectividade. Algumas notas sobre "o perspectivismo de Nietzsche".

seu contra sob controle e deles poder dispor: de modo a saber utilizar em prol do conhecimento a diversidade de perspectivas e interpretações afetivas" (GM/GM III, 12, KSA 5.364f. Trad. Paulo César de Souza, p. 108 e 109) permite uma leitura diferente se levarmos em consideração o que ele diz sobre a amplidão e estreiteza, justiça ou injustiça, das perspectivas. Como em GM/GM III, 12 (e Nachlass/PF 1886, 7[60], KSA 12.315), Nietzsche associa perspectivas com um certo pró e contra no prefácio para MA/HH quando fala da "injustiça necessária de todo pró e contra" (MA I/ HH I, Prefácio 6, KSA 2.20. Trad. Rubens Rodrigues Filho, Os pensadores, 1974, p. 97). Nesse ponto, ele introduz uma diferença entre injustiça "mais estreita" e "mais ampla", o que pode ser associada com o tema de possuir poder sobre os seus "prós e contras". Isto corresponde à sua interpretação de justiça como uma "função de uma potência de ampla visão, que vê acima das pequenas perspectivas do bem e do mal, que tem portanto um amplo horizonte da vantagem" (Nachlass/PF 1884, 26[149], KSA 11.188). Note que justiça é descrita aqui num horizonte mais amplo de interesse quando comparado com as perspectivas mais estreitas, uma função do poder e não como algo sem interesse ou somente referida a algum tipo de objeto. Quando Nietzsche fala em amplidão ou justiça no contexto das perspectivas, essas noções não parecem implicar o aumento da adequação a um objeto subjacente, mas, pelo contrário, invocam a imagem de um horizonte mais amplo que compromete (ou que não é mais limitado) os prós e contras daquelas mais limitadas e podem, até um determinado grau, possibilitar o surgimento de perspectivas conflitantes (cf. Nachlass/PF 1884, 26[359], KSA 11.244).

Numa nota de 1885, Nietzsche primeiramente sustenta que qualquer ser ou "o que é isso" é uma "postulação" perspectivística e pressupõe multiplicidade: “o 'o que é isso?' constitui uma postulação de sentido a partir da perspectiva de algo outro. A 'essência', a 'essencialidade', é algo perspectivístico e já pressupõe uma multiplicidade" (Nachlass/PF 1885, 2[149], KSA 12.140. Trad. 
Flávio Kothe, Fragmntos finais, 2002, p. 159) Ele então passa para a questão da combinação de múltiplas perspectivas: "uma coisa estaria designada somente quando todos os entes tivessem perguntado e respondido 'o que é isso?'. Digamos que falte um único ente com as suas relações e perspectivas peculiares em relação a todas as coisas: e tal coisa não estaria ainda bem definida" (ibid.) Eu gostaria somente de destacar dois aspectos aqui: primeiro, essa passagem indica que as perspectivas constituem o "objeto" ao invés de serem representações mais ou menos exatas dele. Se fosse este último, quase não faria diferença se, presumidamente, uma das inúmeras perspectivas estivesse ou não faltando. Segundo, o texto parece implicar que o "que é isso?" de um ser a respeito de uma coisa, de alguma forma depende das relações e perspectivas desse ser com todas as outras coisas ("Perspektiven zu allen Dingen"). Qualquer "o que é isso?" pressuporia, portanto, multiplicidade na medida em que isso é dependente de todas as demais relações interpretativas. Manter que algo é "isto e aquilo" inevitavelmente simplificaria a infinita, flutuante complexidade das relações interpretativas que "definem" o que "algo é".

$\mathrm{O}$ famoso verso "quanto mais afeto permitirmos falar sobre uma coisa, quanto mais olhos, diferentes olhos, soubermos utilizar para essa coisa, tanto mais completo será nosso 'conceito' dela, nossa 'objetividade" (GM/GM III, 12, KSA 5.365. Trad. Paulo César de Souza, p. 109) pode, portanto, ser entendido diferentemente: de modo distinto àquilo que a analogia visual sugere, aumentar a "objetividade" não significaria a revelação de mais características do objeto que existe anteriormente às várias perspectivas que podemos ter dele, mas, pelo contrário, desperta o esclarecimento sobre os diversos panos de fundo das interpretações e suas interações discursivas que constituem o "objeto", um esclarecimento referente às "forças ativas e interpretativas, as quais fazem com que ver seja ver-algo" (ibid.) ${ }^{32}$.

32 Uma interpretação similar deste tema foi sugerida por Tracy Strong, 1985, p.172. 
Relendo a perspectividade. Algumas notas sobre "o perspectivismo de Nietzsche".

A questão da autorreferência

A questão da autorreferência é uma das questões mais notórias em torno do "perspectivismo de Nietzsche". Eu terei de me restringir a alguns breves comentários aqui e não entrarei em detalhes sobre os diversos caminhos em que essa questão foi posta, respondida ou circunscrita pelos comentadores. Basta lembrar que se "perspectivismo" é tido como uma expressão para a situação em que não há fatos, somente interpretações, pode parecer que incorre numa inconsistência autorreferida: tudo o que Nietzsche fala sobre o perspectivístico não seria perspectivístico em si mesmo? E isso não faria de sua crítica da, por exemplo, moral cristã, também uma mera perspectiva? Enquanto se pode responder que isso, na verdade, somente confirmaria o "perspectivismo" ao invés de contradizê$\mathrm{lo}^{33}$, muitos comentadores ficam desconfortáveis com esse tipo de circularidade e muito esforço foi dispendido com diferentes estratégias para evitá-lo. Surpreendentemente poucos perguntaram se Nietzsche, no final das contas, compartilhava esse sentimento.

Sobre as implicações da crítica de Nietzsche sobre a moralidade cristã, ele realmente usa para descrever seu "Umwertung", os termos "perspectiva" e o intimamente relacionado "Optik", situando-o assim numa dicotomia entre saúde e doença ao invés de verdade e falsidade (cf. EH/EH Por que sou tão sábio 1, KSA 6.266; cf. Nachlass/PF 1888, 24[1], KSA 13.631). No final de WA/CW, ele recorre ao mesmo vocabulário de valor ótico, saúde e doença e rejeita explicitamente que sua oposição ao cristianismo está baseada na distinção entre verdadeiro e falso:

33 Como sugerido por Martin Heidegger (1961, p.501 e seg.) com relação à tese de que a verdade é uma forma de ilusão. Seguindo a visão de Karl Jasper de que Nietzsche dá uma "interpretação da interpretação" (1950, p.296), comentadores como Wolfgang MüllerLauter (1974), Josef Simon (1981), Günther Abel (1984) ou Werner Stegmaier (2004) desenvolveram abordagens sofisticadas para lidar com os aspectos da autorreferência no pensamento nietzschiano ao invés de condená-los como "inconsistentes" ou "contraditórios". Infelizmente, estas abordagens são, na maior parte das vezes, ignoradas em debates recentes. 
São ambas necessárias, tais formas contrárias na ótica dos valores: são maneiras de ver, em que razões e refutações não influem. Não se refuta o cristianismo, não se refuta uma doença dos olhos. Combater o pessimismo como uma filosofia foi o apogeu da estupidez erudita. As noções de "verdadeiro" e "não-verdadeiro" não possuem, a meu ver, qualquer sentido na ótica" (WA/CW Epílogo, KSA 6.51. Trad. Paulo César de Souza, p. 44).

Nietzsche não parece aqui se preocupar em apresentar seu ponto de vista como uma perspectiva diferente ao invés de "verdadeira", e enquanto é inegável que em seus últimos trabalhos ele parece reivindicar a verdade ousadamente por vezes, isto pode muito bem ser uma reação estratégica às reinvindicações de verdade feitas pela perspectiva cristã ("Se a mendacidade reivindica a todo preço a palavra "verdade" para a ótica [...] EH/EH, Por que sou um destino, 5, KSA 6.370. Trad. Paulo César de Souza, p. 113).

Minha principal preocupação aqui é se devemos considerar as declarações de Nietzsche sobre o perspectivístico como sendo perspectivísticas nelas mesmas e o que isto significaria. Enquanto vemos diversos textos que refletem as implicações autorreferenciais de sua crítica do conhecimento, verdade e linguagem, me aterei aqui a duas passagens que explicitamente giram em torno dos termos "Perspektivismus" e "perspektivisch".

No final de FW/GC 354, a categoria de utilidade, que conduz o argumento, e dá base para a sua tese sobre o "fenomenalismo e perspectivismo", se volta contra si mesma: "sabemos' (ou acreditamos ou imaginamos) precisamente o tanto que, no interesse do rebanho humano, da espécie, pode ser útil: até mesmo o que aqui é denominado 'utilidade' é, por último, simplesmente uma crença, uma imaginação e, talvez, precisamente aquela estupidez, a mais fatal de todas, de que um dia sucumbiremos" (FW/GC 354, KSA 3.593. Trad. Rubens Rodrigues Filho, Os pensadores, 1974, p. 226). Ao colocar em questão a categoria de utilidade como mera crença, ilusão ou tolice (termos que aludem à explicação do perspectivismo), 
Relendo a perspectividade. Algumas notas sobre "o perspectivismo de Nietzsche".

Nietzsche esclarece que a análise do perspectivismo não é feita de uma certa metaposiçao neutra que permanece protegida da "corrupção, falsificação, superficialização e generalização"(ibid.). Ao invés disso, os textos parecem enredados pela própria dificuldade que buscam descrever. Seu caráter autorreferencial já é transparente quando Nietzsche declara "que nosso pensamento mesmo, pelo caráter da consciência [...] é constantemente como que majorizado e retraduzido para a perspectiva do rebanho" (ibid., 592. ibid. p. 225) pois a expressão "nosso pensamento" pode ser relacionada tanto ao pensamento consciente em geral quanto ao pensamento que Nietzsche está articulando e ao qual ele se refere explicitamente usando o mesmo termo: "meu pensamento é, como se vê [...]" (ibid.). A autorreferencialidade aparece, inclusive, na própria introdução do perspectivismo enquanto tal, na qual Nietzsche se refere ao "fenomenalismo e perspectivismo, assim como eu o entendo" (ibid., 593, ibid. 225). Destacando que este é o seu entendimento do perspectivismo, ele não só o relaciona ao seu próprio ponto de vista, mas também cria uma tensão autoirônica, pois algumas linhas acima ele negou a mera possiblidade de algo como um entendimento "individual".

Em FW/GC 374, as implicações autorreferenciais são colocadas mais explicitamente quando Nietzsche argumenta que qualquer autoexame do intelecto humano inevitavelmente termina vendo a si mesmo sob suas próprias formas perspectivas:

Até onde vai o caráter perspectivista da existência, ou mesmo se ela tem algum outro caráter, se uma existência sem interpretação, sem "sentido", não vem a ser justamente "absurda", se, por outro lado, toda a existência não é essencialmente interpretativa — isso não pode, como é razoável, ser decidido nem pela mais diligente e conscienciosa análise e autoexame do intelecto: pois nessa análise o intelecto humano não pode deixar de ver a si mesmo sob suas formas perspectivas e apenas nelas (FW/GC 374, KSA 3.626. Trad. Paulo César de Souza, p. 278). 
Note que a circularidade serve aqui como uma explicação para o porquê nós somos incapazes de determinar o alcance do caráter perspectivo do nosso ser. Isso nos previne de afirmar ousadamente que todo ser é essencialmente interpretativo. Nietzsche, nesse ponto, se limita antes à afirmação (aparentemente) mais moderada de que nós não podemos evitar a possibilidade de que o mundo englobe uma infinita possibilidade de interpretações: "O mundo tornouse novamente infinito para nós: na medida em que não podemos rejeitar a possibilidade de que ele encerre infinitas interpretações" (ibid., p.627). Determinar o alcance do caráter perspectivístico do ser significaria oferecer uma crítica do conhecimento num sentido kantiano, uma clara, decisiva determinação das limitações do intelecto humano através da autorreflexão. Ainda assim, para Nietzsche, é precisamente isso que se tornou impossível pelo fato do perspectivístico não poder ser superado ou transcendido em direção a um metanível estável de análise. Talvez é essa autorreferenciabilidade o fato de que qualquer indagação dentro do caráter perspectivístico do nosso entendimento deva em si mesma permanecer perspectivística, o que previne Nietzsche de desenvolver o perspectivismo como uma outra doutrina ou uma rigorosa teoria do conhecimento. A necessidade do perspectivístico em qualquer "Für-wahr-halten" parece subverter a estabilidade discursiva de qualquer estrutura filosófica, incluindo aquelas usadas para demonstrar essa necessidade, e sabota, portanto, a própria possibilidade em propor "doutrinas" ou "teorias" filosóficas num sentido tradicional ${ }^{34}$. Certamente podemos, contudo, optar por rotular essa visão, ou o estilo de pensamento que disso decorre, de "Perspektivismus"35. Nós devemos, de qualquer modo, ter em

34 Como coloca Tracy Strong (1985, p.177), „O Perspectivismo não pode ser uma doutrina ou ponto de vista porque, entendida de forma adequada, impossibilita o ativismo epistemológico que uma doutrina requer" Cf. GOEHR, 2010, p.35.

35 Para leituras nessa direção, ver BRÄUTIGAM, 1977 e NEHAMAS, 1985. 
mente que "Perspektivismus", nesse sentido, não é a doutrina epistemológica de Nietzsche, mas, antes, o que o impede de apresentar tal doutrina.

\begin{abstract}
This paper contrasts common understandings of "Nietzsche's perspectivism" with his use of the word "Perspektive" and related wordforms. The first sections provide a brief survey of the development of different meanings throughout Nietzsche's career and the influence of Gustav Teichmüller. The next sections unfold some problems of common readings of perspectivism as Nietzsche's theory of knowledge. Discussing the issues of falsification, objectivity and self-reference, the remaining sections lead to the conclusion that perspectivsm should not be understood as Nietzsche's doctrine of epistemology but rather as what keeps him from providing such a doctrine.

Keywords: perspectivism - falsification - objectivity - self-reference - Teichmüller
\end{abstract}

\title{
referências bibliográficas:
}

1. ABEL, G. Nietzsche. Die Dynamik der Willen zur Macht und die ewige Wiederkehr. Berlin: de Gruyter, 1984.

2. ABEL, G. Wahrheit als Interpretation. In: ABEL, G., SALAQUARDA, J.; MÜLLERLAUTER, W. (org.). Krisis der Metaphysik. Wolfgang Müller-Lauter zum 65. Geburtstag. Berlin: de Gruyter, 1989, p.331-363.

3. BRÄUTIGAM, B. Verwegene Kunststücke. Nietzsches ironischer Perspektivismus als schriftstellerisches Verfahren. In: Nietzsche-Studien, n. 6, p. 45-63, 1977.

4. BROBJER, T. Nietzsche's Philosophical Context. An Intellectual Biography. Urbana, Ill.: Univ. of Illinois Press, 2008.

5. CASPARI, O. Der Zusammenhang der Dinge. Gesammelte philosophische Aufsätze. Breslau: Trewendt, 1881.

6. CLARK, M. Nietzsche on Truth and Philosophy. Cambridge: Cambridge Univ. Press, 1990.

7. COKER, J. Construing Perspectivism. In: International Studies in Philosophy, n.34, p. 5-28, 2002. 
8. COX, C. Nietzsche. Naturalism and Interpretation. Berkeley: Univ. of California Press, 1999.

9. DELLINGER, J. Perspektivismus. In: NIEMEYER, C. (org.) Nietzsche-Lexikon. Darmstadt: WBG, 2009, p. 266-267.

10. GEMES, K. Janaway on Perspectivism. In: European Journal of Philosophy, n.17, p.101-112, 2009.

11. GOEHR, L. Perspektivismus ohne Perspektive oder: Philosophie ohne Kunst. Mit Nietzsches fröhlicher Wissenschaft auf der Bühne stehen. In: KOCH, G. (org.) Perspektive - Die Spaltung der Standpunkte. Zur Perspektive in Philosophie, Kunst und Recht. München: Fink, 2010, p.29-48.

12. GREEN, M. Nietzsche and the Transcendental Tradition. Urbana, Ill.: Univ. of Illinois Press, 2002.

13. HEIDEGGER, M. Nietzsche. Vol. 1. Pfullingen: Neske, 1961.

14. JANAWAY, C. Beyond Selflessness. Reading Nietzsche's Genealogy. Oxford: Oxford Univ. Press, 2007.

15. JASPERS, K. Nietzsche. Einführung in das Verständnis seines Philosophierens. Berlin: de Gruyter, 1950.

16. LEITER, B. Perspectivism in Nietzsche's ,Genealogy of Morals'. In: SCHACHT, R. (org.) Nietzsche, Genealogy, Morality. Essays on Nietzsche's 'Genealogy of Morals'. Berkeley: Univ. of California Press, 1994, p.334-357.

17. MÜLLER-LAUTER, W. Nietzsches Lehre vom Willen zur Macht. In: NietzscheStudien, n.3, p.1-60, 1974.

18. NEHAMAS, A. Nietzsche. Life as Literature. Cambridge Mass.: Harvard University Press, 1985.

19. NOHL, H. Eine historische Quelle zu Nietzsches Perspektivismus: G. Teichmüller, die wirkliche und die scheinbare Welt. In: Zeitschrift für Philosophie und philosophische Kritik, n.149, p.106-115, 1913.

20. SCHWENKE, H. Zurück zur Wirklichkeit. Bewusstsein und Erkenntnis bei Gustav Teichmüller. Basel: Schwabe, 2006.

21. SIMON, J. Friedrich Nietzsche. In: HÖFFE, O. (org.) Klassiker der Philosophie. München: Beck, 1981, p.203-224.

22. SIMON, J. Der gewollte Schein. Zu Nietzsches Begriff der Interpretation. In: DJURIC, M., SIMON, J. (org.) Kunst und Wissenschaft bei Nietzsche. Würzburg: Königshausen und Neumann, 1986, p.62-74,

23. SMALL, R. Nietzsche in Context. Aldershot: Ashgate, 2001.

24. STEGMAIER, W. Nietzsches und Luhmanns Aufklärung der Aufklärung: Der Verzicht auf ,die Vernunft‘. In: RESCHKE, R. (org.) Nietzsche. Radikalaufklärer oder radikaler Gegenaufklärer? Berlin: Akademie, 2004, p.167-178.

154 | cadernos Nietzsche 31,2012 
Relendo a perspectividade. Algumas notas sobre "o perspectivismo de Nietzsche".

25. STRONG, T. B. Texts and Pretexts. Reflections on Perspectivism in Nietzsche. In: Politcal Theory, n.13, p.164-182, 1985.

26. TEICHMÜLLER, G. Darwinismus und Philosophie. Dorpat: Mattiesen, 1877.

27. TEICHMÜLLER, G. Über das Wesen der Liebe. Leipzig: Duncker \& Humblot, 1879.

28. TEICHMÜLLER, G. Über die Reihenfolge der platonischen Dialoge. Leipzig: Köhler, 1879.

29. TEICHMÜLLER, G. Die wirkliche und die scheinbare Welt. Neue Grundlegung der Metaphysik. Breslau: Koebner, 1882.

30. Zittel, C. Das ästhetische Kalkül von Friedrich Nietzsches Also sprach Zarathustra. Würzburg: Königshausen \& Neumann, 2000.

Artigo recebido em 17/05/2011. Artigo aceito para publicação em 16/06/2011. 